\title{
SÍNDROME DE SUSAC DE PRESENTACIÓN OCULAR ATÍPICA
}

\section{ATYPICAL OPHTHALMIC FINDINGS IN SUSAC SYNDROME}

\author{
AVIÑÓ JA ${ }^{1}$, ESPAÑA E ${ }^{2}$, PERIS-MARTÍNEZ C ${ }^{3}$, MENEZO JL ${ }^{4}$
}

\section{RESUMEN}

Caso clínico: Mujer de 25 años de edad afecta de encefalopatía y pérdida auditiva neurosensorial, remitida a nuestro servicio para confirmar un síndrome de Susac por presentar una disminución de agudeza visual bilateral. En la exploración funduscópica se apreció una microangiopatía retiniana periférica.

Discusión: El síndrome de Susac se caracteriza típicamente por la tríada encefalopatía, perdida auditiva neurosensorial, y oclusiones de ramas arteriales retinianas. En nuestro caso las alteraciones oculares eran atípicas, apreciándose amputación de vasos terminales con cúmulo de microaneurismas en retina periférica de ambos ojos.

Palabras clave: Oclusión de ramas arteriales retinianas, microangiopatía, síndrome de Susac, encefalopatía, pérdida auditiva.

\section{ABSTRACT}

Case report: A 25-year-old woman with encephalopathy and sensorineural hearing loss was referred to us in order to confirm Susac syndrome, due to bilateral visual loss. Funduscopic examination revealed peripheral retinal microangiopathy.

Discussion: Susac syndrome is typically characterized by the clinical triad of encephalopathy, branch retinal artery occlusions, and hearing loss. In our case, ophthalmic findings were atypical. Interrupted vessels and microaneurisms accumulation in the peripheral retina of both eyes were observed (Arch Soc Esp Oftalmol 2007; 82: 179-182).

Key words: Branch retinal artery occlusion, microangiopathy, Susac syndrome, encephalopathy, hearing loss.

\section{INTRODUCCIÓN}

El síndrome de Susac consiste en una microangiopatía del cerebro, retina y cóclea, y está caracterizado típicamente por la tríada clínica de encefalopatía, oclusiones de ramas arteriales retinianas, y pérdida auditiva (1). El síndrome afecta típicamente a mujeres jóvenes de entre 20 y 40 años de edad y tiene una frecuencia muy baja, habiéndose descrito menos de cien casos en la literatura mundial. Su etiología es desconocida, aunque se han propuesto muchas teorías: vasculitis con desórdenes autoin-

\footnotetext{
Recibido: 8/5/06. Aceptado: 13/2/07.

1 Doctor en Medicina. Servicio de Oftalmología. Hospital Universitario La Fe. Valencia.

2 Doctor en Medicina. Escuela de Óptica. Universidad de Valencia. Servicio de Oftalmología. Hospital Universitario La Fe. Valencia.

3 Doctora en Medicina. Fundación Oftalmológica del Mediterráneo (FOM). Valencia.

4 Doctor en Medicina. Fundación Oftalmológica del Mediterráneo (FOM). Valencia. Servicio de Oftalmología. Hospital Universitario La Fe. Valencia.
} 
munes, anormalidades de la coagulación y microembolización $(1,2)$. El blanqueamiento retiniano isquémico provocado por las oclusiones arteriales es el hallazgo funduscópico más frecuente en el síndrome de Susac.

Presentamos el caso de una paciente con síndrome de Susac con hallazgos oculares atípicos.

\section{CASO CLÍNICO}

Una mujer de 25 años de edad fue remitida a nuestro servicio para confirmar la presencia de un síndrome de Susac, debido a una pérdida visual bilateral. La paciente tenía una historia de alteraciones del equilibrio, ataxia, incontinencia fecal y urinaria, y pérdida auditiva izquierda desde hacía cuatro años, y estaba recibiendo corticoides, nimodipino y anticoagulantes. En el examen neurológico se apreciaba una paraparesia espástica, hiperreflexia tendinosa y disfunción genitourinaria. La analítica sanguínea que incluía hemograma, bioquímica general, velocidad de sedimentación globular, enzima conversor de la angiotensina y coagulación resultaba sin alteraciones. La serología de lúes, virus de la inmunodeficiencia humana, herpes simple, hepatitis $\mathrm{B}$ y $\mathrm{C}$, proteína $\mathrm{C}$ reactiva, factor reumatoide, anticoagulante lúpico, anticuerpos antinucleares, anticardiolipina, y antifosfolípido fue negativa. La radiografía de tórax, electrocardiograma, ecocardiografía y tomografía axial computerizada craneal no presentaban alteraciones. El líquido cefalorraquídeo (LCR) era de aspecto claro y con presión de apertura normal, con ligero aumento de proteínas, y resto de fórmula normal. La serología en LCR para borrelia, virus de Epstein-Barr, citomegalovirus y lúes, además de los cultivos habituales resultaron negativos. La detección de bandas oligoclonales en el mismo también resultó negativa. La Resonancia Magnética Nuclear (RMN) cerebral mostraba múltiples áreas focales de hiperintensidad en la sustancia blanca periventricular y pericallosa, $\mathrm{y}$ en las regiones del centro semioval (fig. 1). Los tests audiométricos estándares revelaron pérdida auditiva neurosensorial, asimétrica, de predominio izquierdo, para las bajas frecuencias. A la exploración oftalmológica, su agudeza visual era de 20/25 en ambos ojos. La campimetría de Goldmann (Haag-Streit, Berna, Suiza) mostró una cuadrantanopsia inferior bitemporal. En la biomicroscopía del segmento anterior no se apreciaban hallazgos

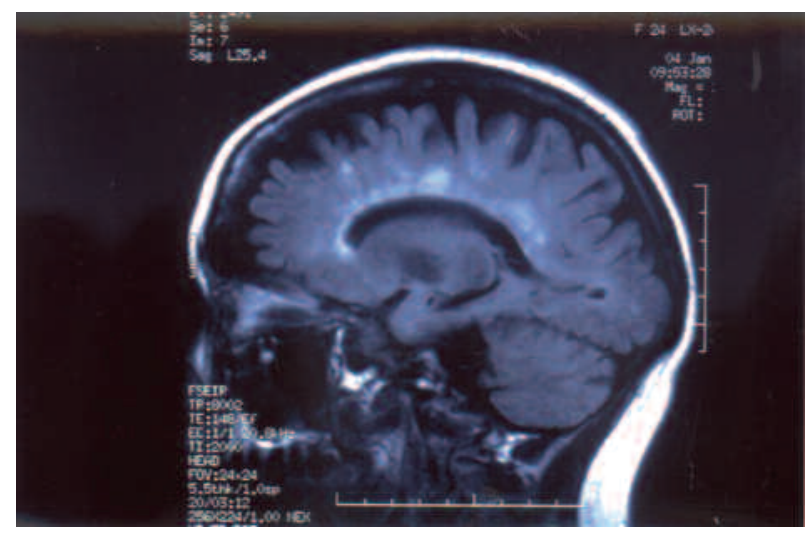

Fig. 1: Imagen de un corte sagital de RMN cerebral en secuencia ponderada en T1. Se aprecian múltiples áreas de hiperintensidad en el cuerpo calloso.

destacables. El examen funduscópico reveló una microangiopatía retiniana periférica, apreciándose amputación de vasos con cúmulos de microaneurismas en ambos ojos (fig. 2). No se observaron signos de inflamación o células en el vítreo, ni envainamiento de los vasos retinianos. La angiografía fluoresceínica (AGF) demostró signos de isquemia en las áreas correspondientes a las oclusiones arteriolares (fig. 3). El diagnóstico de síndrome de Susac se basó en la asociación de encefalopatía con hallazgos típicos en la RMN, microangiopatía retiniana y pérdida auditiva neurosensorial.

Debido a la evidente isquemia retiniana periférica apreciada en la AGF, se le realizó fotocoagulación retiniana con láser en las áreas isquémicas de forma profiláctica, manteniéndose estable el cuadro

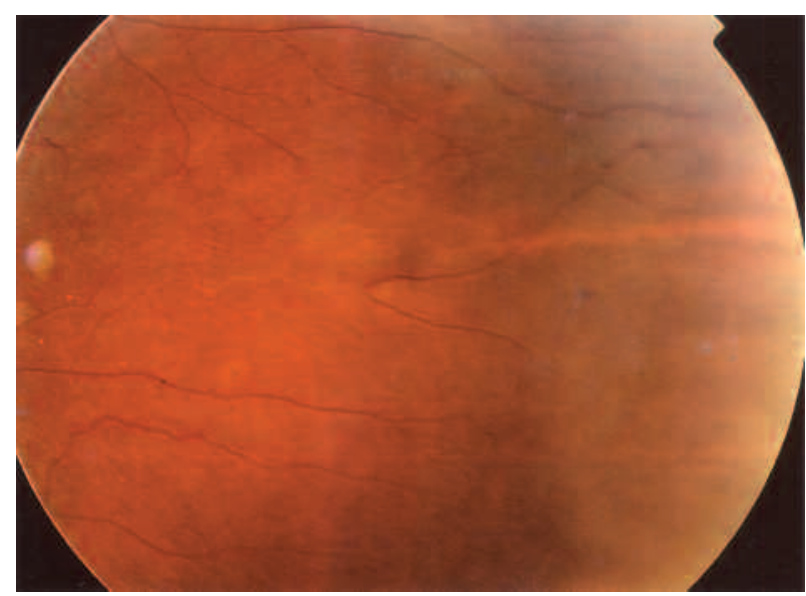

Fig. 2: Retinografía del ojo izquierdo. Nótense cúmulos de microaneurismas y amputación terminal de los vasos. 


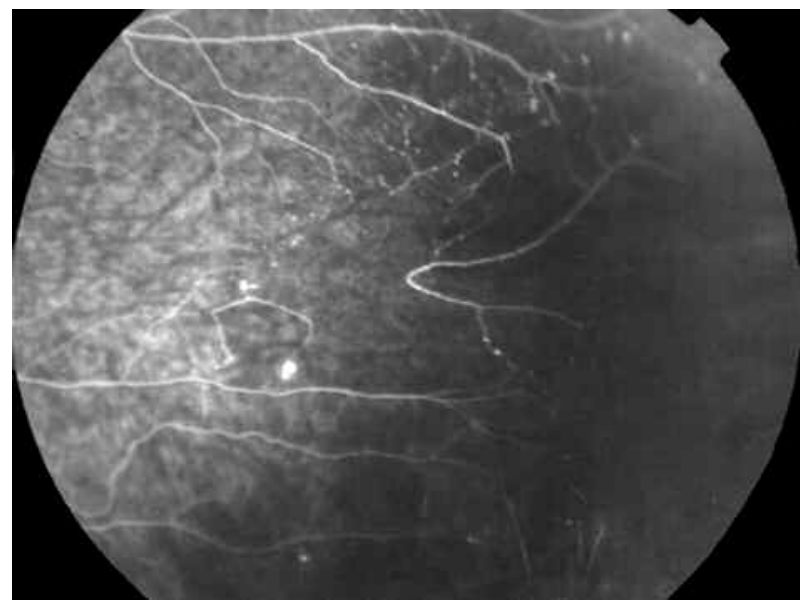

Fig. 3: Angiograma fluoresceínico del ojo izquierdo. En la retina periférica temporal se observan áreas de isquemia.

visual desde entonces. Al cabo de dos años no ha habido variaciones significativas tanto en el estado neurológico como auditivo.

\section{DISCUSIÓN}

Nuestro paciente presenta afectación microangiopática del cerebro, cóclea y retina que se ajusta a la descripción del síndrome de Susac (1). Los hallazgos de la RMN están completamente en concordancia con los descritos en este síndrome, con lesiones en la sustancia blanca cerebral (periventricular, centro semioval) con especial afectación del cuerpo calloso (3). Sin embargo, los hallazgos oftálmicos son en cierta medida atípicos, ya que no incluyen las típicas oclusiones de ramas arteriales retinianas, placas de pared arterial, o tinción de los vasos en la AGF $(1,2,4,5)$. En nuestro caso, los vasos amputados rodeados por microaneurismas observados en la retina periférica de ambos ojos evidenciaban la microangiopatía retiniana (fig. 1), que se mostraba con signos de isquemia en la angiografía (fig. 3).

El diagnóstico diferencial debe incluir diferentes procesos inmunológicos como vasculitis, lupus eri- tematoso sistémico, enfermedad de Behçet, sarcoidosis, diferentes coagulopatías, procesos neoplásicos como el linfoma e infecciones como sífilis, borreliosis, tuberculosis y viriasis $(1,2,4)$. Cabe destacar las frecuentes confusiones diagnósticas con la esclerosis múltiple, con la que comparte muchas similitudes tanto clínicas como en la RMN. Este despistaje es particularmente importante pues el diagnóstico del síndrome de Susac es estrictamente clínico y no hay ningún marcador específico conocido.

La patogenia es desconocida, y la eficacia del tratamiento incierta, aunque los más aceptados incluyen corticoides y antiagregantes, como en el caso de nuestra paciente. Además entre otras opciones destacan la ciclofosfamida, calcio antagonistas, plasmaféresis e inmunoglobulinas $(2,4)$.

Los oftalmólogos deberían conocer y tener presente este síndrome infrecuente y muchas veces no diagnosticado, de origen desconocido, ya que puede resultar en pérdida visual. Asimismo cabe destacar que los hallazgos oftalmológicos puedes ser muy sutiles, con síntomas visuales mínimos o prácticamente inexistentes, sin llegar a presentar las típicas oclusiones de ramas arteriales retinianas, debiendo ser minuciosos en la exploración funduscópica cuando se sospeche este síndrome.

\section{BIBLIOGRAFÍA}

1. Susac JO. Susac's syndrome: the triad of microangiopathy of the brain and retina with hearing loss in young women. Neurology 1994; 44: 591-593.

2. O'Halloran HS, Pearson PA, Lee WB, Susac JO, Berger $J R$. Microangiopathy of the brain, retina, and cochlea (Susac syndrome). A report of five cases and a review of the literature. Ophthalmology 1998; 105: 1038-1044.

3. Susac JO, Murtagh FR, Egan RA, Berger JR, Bakshi R, Lincoff $N$, et al. MRI findings in Susac's syndrome. Neurology 2003; 61: 1783-1787.

4. Egan RA, Ha Nguyen T, Gass JD, Rizzo JF 3rd, Tivnan J, Susac JO. Retinal arterial wall plaques in Susac syndrome. Am J Ophthalmol 2003; 135: 483-486.

5. Murata Y, Inada K, Negi A. Susac syndrome. Am J Ophthalmol 2000; 129: 682-684. 